 política de la vida bajo el régimen de Augusto Pinochet
}

\section{Heraldo Muñoz}

Santiago, Editorial Planeta, 2009, 415 pp.

Han transcurrido dos décadas desde el cambio de régimen político en Chile y las cuatro administraciones presidenciales que hubo desde entonces han convergido en restaurar el modus vivendi democrático-representativo que caracterizaba al sistema político nacional. Reconfigurar la tolerancia ideológica, fomentar y preservar los derechos de las personas y bregar por acuerdos sustantivos en la redemocratización social y política de Chile ha tomado y seguirá tomando un buen tiempo. La nueva administración presidencial que empieza este 2010 tendrá que hacerse cargo del mismo compromiso en los años que vienen. Ello porque la experiencia de los casi 17 años de régimen militar constituye un caso único en la historia chilena, sin precedentes en su estilo, en su duración y en sus complejas implicaciones. De ello se hace cargo el libro del doctor Heraldo Muñoz, el cual comentamos en esta ocasión.

Visto en perspectiva, los primeros efectos de los cambios estructurales en el ámbito económico-social y del desarrollo político-institucional de Chile durante el segundo tercio de los años sesenta del siglo pasado estimularon la puesta en marcha de un singular proceso, sumamente envolvente hacia finales de esa década y crecientemente polarizado en el primer tercio de los años setenta. Ese proceso es abrupta e inopinadamente 
suspendido con un golpe de Estado en septiembre de 1973. Bastante se ha declamado e investigado en torno a los doce años que anteceden a la instauración del régimen militar, ensayos y escritos en los cuales predomina la interpretación ideológica de los hechos o una enmarañada recopilación de experiencias personales. Pero también hay un apreciable volumen de publicaciones en torno a las sinuosas vicisitudes de la redemocratización del país desde 1990, abundando esta vez las conclusiones de corte académico, las que sin desmerecer legítimas posiciones ideológicas, encuadran más y en mejor forma el análisis de los datos y de la documentación disponible. Llegará el día en que leamos ensayos, investigaciones u obras cuyo hilo conductor explique con mayor rigor y menos pasión esos casi 50 difíciles años, durante los cuales nuestra sociedad enfrentó cambios y contra-cambios que en Europa occidental tomaron casi dos siglos.

Las dificultades políticas internas y externas de las que tuvo que hacerse cargo la administración del Presidente Salvador Allende constituyen el punto de partida para entender cabalmente el contexto histórico del análisis. El autor dedica una parte de su libro a este convulsionado período, pero creemos que debió extenderse más y con mayor detalle. Los hechos políticos se enmarcan en tiempos y situaciones reales, en los cuales existe una concreta relación causa-efecto.

En tal sentido hay que recordar que la incomprensión y la excesiva presión ideológica provenientes de la coalición gobernante acotaron el radio de acción de la gestión presidencial, imposibilitando entonces los necesarios -urgentes, en un determinado momento- acuerdos de gobernabilidad. No obstante algunos intentos, los deficientes resultados de la política económica y una in crescendo beligerancia interna acentuaron la mutua descalificación entre oficialismo y oposición. Esta agudizada polarización del país presagiaba inevitablemente la montée des tenèbres, la que a la postre abrió paso a uno de las más violentos y radicales golpes de Estado que registra la historia latinoamericana.

Las implicaciones del proceso interno también se proyectaban en el ámbito exterior del país y ello desde dos ópticas. Por lo pronto había una manifiesta animadversión del gobierno norteamericano hacia a gestión del Presidente Allende, tema 
sobre el cual abunda el autor, con bastante propiedad. Coincidimos con él en que esa postura colaboró en acrecentar la sensación de inminencia del golpe de Estado de 1973. La diplomacia chilena desplegó resguardo y prudencia en los vínculos bilaterales, actitud que no fue seguida por su homónima norteamericana. Como es sabido, desde mediados de 1972 varias agencias gubernamentales de los Estados Unidos no pararon mientes en socavar la frágil sustentabilidad del gobierno chileno.

Con todo, una pléyade de gobiernos y fuerzas políticas europeo-occidentales asumieron hacia el gobierno del Presidente Allende un comportamiento deferente, más flexible y menos inquisitivo, como lo pone de relieve el autor. Más aún, varios de esos gobiernos reforzaron su cercanía acrecentando programas de asistencia técnica y de ayuda al desarrollo, al mismo tiempo que diversos grupos y partidos políticos de la izquierda europeo-occidental no ocultaban una clara inclinación por el Presidente Allende y su gestión. El estilo del golpe militar y la reiterada vulneración de los derechos de las personas en Chile causaron enorme estupor en esos gobiernos, los que de ahí en adelante tuvieron una postura crítica hacia el régimen de facto. Esta actitud tuvo como contraparte un persistente apoyo en favor de los sectores opuestos al régimen militar y en pro de la redemocratización de Chile.

Aunque los nexos chileno-norteamericanos durante el período dictatorial han sido latamente analizados por el autor en otro de sus libros, hay una descripción interesante al respecto, no desprovista de alcances personales. Inicialmente, el golpe militar chileno contó con el beneplácito del gobierno de los Estados Unidos, actitud que quedó un tanto trunca al momento de cambiar de administración. Los cuatro años siguientes fueron extremadamente duros hacia el régimen militar, principalmente debido al deterioro de los derechos humanos. Si bien esta situación vuelve a cambiar al llegar otra nueva administración al gobierno norteamericano, esta misma retracta su aproximación hacia su homónimo chileno y lo fustiga fuertemente, sumándose a la postura esgrimida por la mayoría de los gobiernos europeo-occidentales y otros latinoamericanos, varios de estos recientemente redemocratizados al terminar los años ochenta. Ciertamente, el vaivén 
de la diplomacia norteamericana fue sumamente oportuno y útil para impulsar el regreso al régimen democrático-representativo en Chile, al igual que el respaldo de otros muchos países. Con todo, sería interesante auscultar analíticamente esta peculiar actitud pendular del gobierno norteamericano, probablemente más visible al tenor de su estructura institucional, pero percibida como una conducta confusa y ambivalente desde la región latinoamericana.

Las actividades internacionales de los organismos de seguridad del régimen militar están detallada y cabalmente descritas en este libro, ciertamente una de sus partes mejor logradas. Pocos precedentes ha habido en la historia latinoamericana sobre este punto y los que hubo casi siempre fueron de la mano con los servicios de inteligencia de países más poderosos. En cambio, la experiencia del régimen militar chileno fue del todo distinta. En esa ocasión hubo una expresa y premeditada decisión, emanada del alto mando gubernamental, respecto de extender la represión y el control político a personas y grupos de conciudadanos que estaban fuera o expulsados de Chile.

Es dolorosamente paradojal, por cuanto un país como éste, cuya diplomacia e instituciones públicas propugnaron durante años la promoción de los derechos inalienables de las personas y la cooperación regional con vistas a superar el subdesarrollo. No obstante, durante este período oscuro de su historia el gobierno de facto se sumió en corrillos ilegales, organizando redes delictuales de triste memoria.

El crepúsculo del régimen militar está también presente en esta obra. Se aborda de manera documentada y el relato es claro y concluyente. Con todo, creemos que no habría estado demás una perspectiva más politológica sobre, por ejemplo, el rol de las fuerzas armadas en el primer gobierno democrático. Ello es pertinente por cuanto subsisten interrogantes y falta información acerca de los efectos que ha tenido la redemocratización del país en las entidades castrenses. Desde luego, también subsisten fundadas dudas de cuán profundo han calado las virtudes democráticas en cultura cívica y social de Chile. Es motivo para un nuevo estudio. 